\title{
Corrigendum
}

\section{Corrigendum to "Study on the Vibration Effect of Short Footage Blasting Load on Surrounding Rock-Support Structure of Tunnel"}

\author{
Chunquan Dai $(\mathbb{D}$, Hongtao Sui, and Chao Ma \\ School of Civil Engineering and Architecture, Shandong University of Science and Technology, Qingdao, Shandong 266590, China \\ Correspondence should be addressed to Chunquan Dai; dcqwin@sdust.edu.cn \\ Received 10 May 2021; Accepted 10 May 2021; Published 11 June 2021 \\ Copyright (C) 2021 Chunquan Dai et al. This is an open access article distributed under the Creative Commons Attribution License, \\ which permits unrestricted use, distribution, and reproduction in any medium, provided the original work is properly cited.
}

In the article titled "Study on the Vibration Effect of Short Footage Blasting Load on Surrounding RockSupport Structure of Tunnel" [1], due to an error in the preparation of the manuscript, incorrect figures were provided for Figures 6 and 8, which should be corrected as follows:

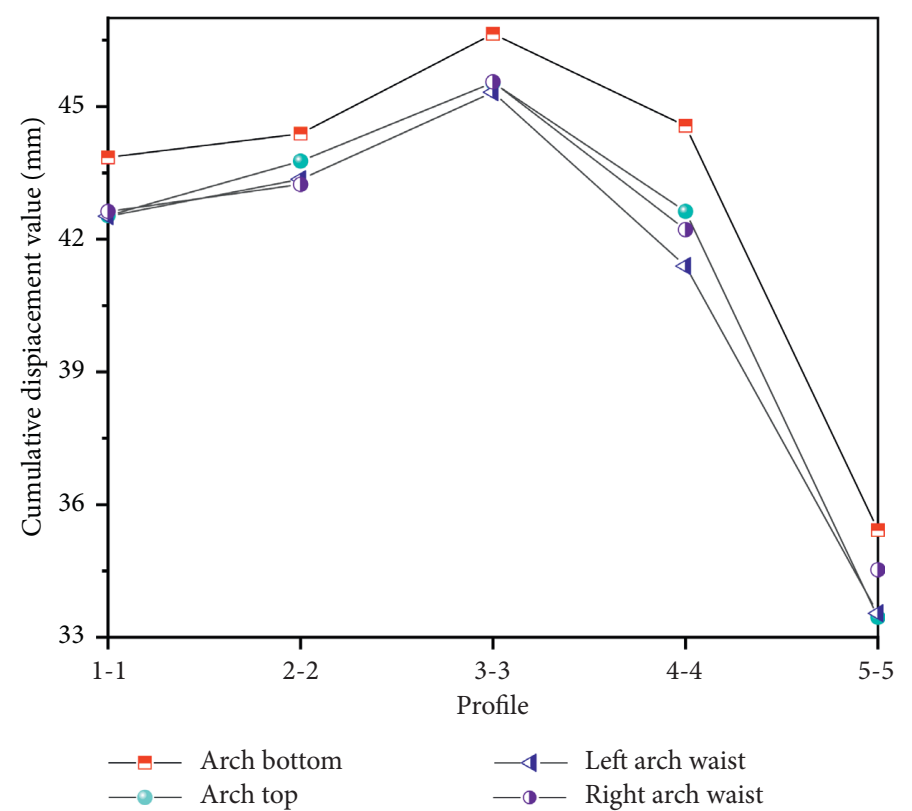

Figure 6: Cumulative displacement values at different measurement points in each profile. 


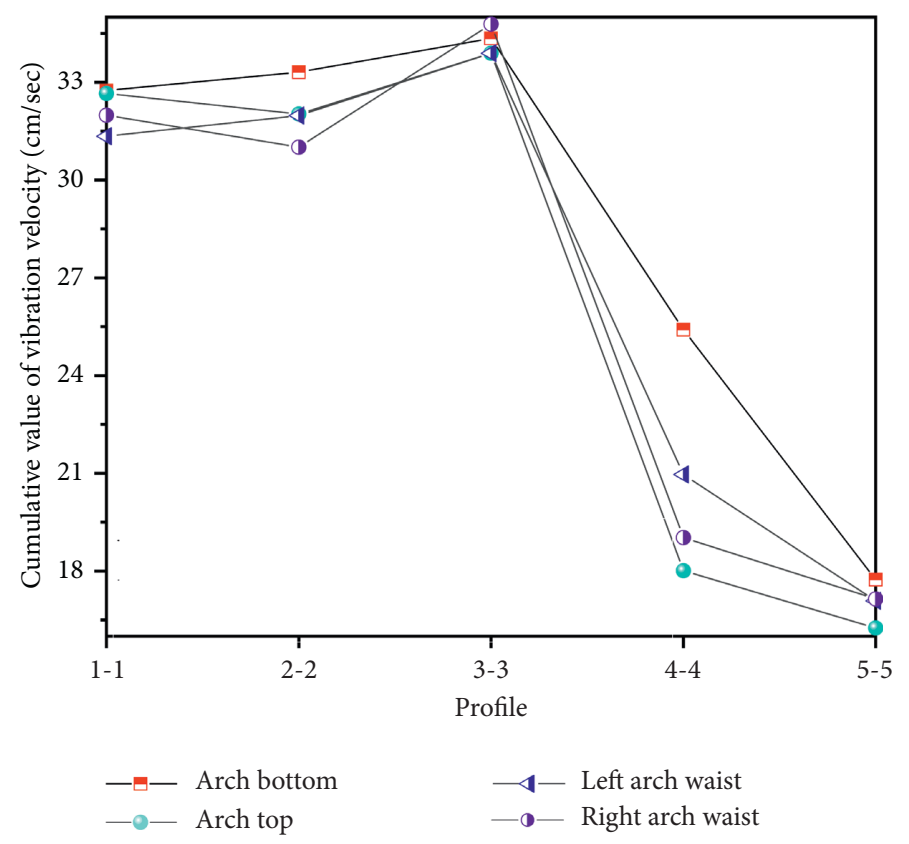

FIGURE 8: Cumulative value of vibration velocity at different measuring points of each section.

\section{References}

[1] C. Dai, H. Sui, and C. Ma, "Study on the Vibration Effect of Short Footage Blasting Load on Surrounding Rock-Support Structure of Tunnel," Shock and Vibration, vol. 2020, Article ID 8829349, 15 pages, 2020. 